\title{
JUDITH BUTLER E HANNAH ARENDT VÃO AO CINEMA: narrativa, psicanálise e subjetivação no filme "Eu, Mamãe e os Meninos"
}

\author{
Ingrid Cyfer*
}

\begin{abstract}
Neste artigo, proponho uma análise do filme Eu, Mamãe e os Meninos (Les garçons et Guillaume, à table! Direção: Guillaume Gallienne. França, 2013) tendo-se em vista uma perspectiva política e relacional das conexões entre psicanálise, narrativa e processo de subjetivação. Minha inspiração para isso está no modo como Judith Butler articula essas dimensões em seu livro Relatar a Si Mesmo: Crítica da Violência Ética ([2005], 2015), no qual a autora propõe uma teoria da formação do sujeito em que a concepção de narrativa de Hannah Arendt cumpre um papel fundamental, depois de ser reformulada pela concepção de self narrável de Adriana Cavarero e combinada à metapsicologia relacional de Jean Laplanche. Desse modo, meu objetivo é convidar Butler e Arendt ao cinema para depois discutir a relação entre narrativa, psicanálise e subjetivação tendo em vista o vínculo entre ética e política que a estória que o personagem Guillaume nos conta sobre quem é pode inspirar.

Palavras-Chave: Hannah Arendt. Judith Butler. Subjetivação. Psicanálise. Narrativa.
\end{abstract}

\section{INTRODUÇÃO}

O cinema, que fabrica sonhos, é contemporâneo da psicanálise, que os interpreta, tendo surgido ambos com a mesma "missão impossível de fundir a ciência e o irracional" (Fernandes, 2005, p.70). Apesar dessas coincidências, Freud, considerado fundador da psicanálise, não era muito receptivo à relação entre psicanálise e cinema. Quando convidado para colaborar com o filme "Segredos da Alma", recusou-se a fazê-lo. Freud temia que o cinema vulgarizasse a psicanálise, que a reprodução imagética do psiquismo o reduzisse a "falsas imitações das coisas brutas” (Fernandes, 2005, p.71). De fato, seu material de trabalho era a palavra. Ao olhar, nenhuma função importante era reservada. Tanto é que o analista, atrás do divã, não busca a conexão com o analisando pela visão, mas sim pela escuta.

No entanto, apesar de sua reticência em tomar a imagem como recurso psicanalítico,

* Universidade Federal de São Paulo (UNIFESP). Escola de Filosofia, Letras e Ciências Humanas (EFLCH).

Estrada do Caminho Velho, 333. Jardim Nova Cidade. Cep: 07252-312. Guarulhos - São Paulo-Brasil. icyfer@unifesp.br https://orcid.org/0000-0002-0992-6403
Freud interpreta sonhos "num cenário composto de imagens semelhantes às de atores num palco", sugerindo talvez que o sonho pudesse ser como um "cinema interior do sonhador (...)” (Ibidem). Mas será que se poderia mesmo comparar o escuro do cinema ao mundo dos sonhos quando estamos dormindo? Será que todo espectador é um pouco como Cecília e Tom Baxter, em "A Rosa Púrpura do Cairo",1 que cruzam a fronteira entre a tela e realidade, entre ator e personagem, entre espectadora e atriz? Ainda que seja preciso certo cuidado para não exagerar nessa sedutora identificação entre psicanálise e cinema, já que os filmes tendem a ter uma narrativa mais lógica e organizada do que o sonho (Fernandes, 2005, p. 72), alguns filmes são particularmente ricos para análises da relação entre psicanálise, narrativa e processo de subjetivação.

O filme "Eu, Mamãe e os Meninos", cujo título original é Les Garçons et Guillaume, à la table,,$^{2}$ parece-me especialmente produtivo

${ }^{1}$ The Purple Rose of Cairo. Direção: Woody Allen. Estados Unidos, 1985.

${ }^{2}$ Les garçons et Guillaume, à table! Direção: Guillaume Gallienne. França, 2013. 
para esse tipo de análise em uma perspectiva política e relacional. Minha inspiração para isso está no modo como Judith Butler ([2005]2015) articula essas dimensões em seu livro Relatar a Si Mesmo: Crítica da Violência Ética. Nessa obra, talvez a formulação mais aprofundada da relação que estabelece entre ética, política e psicanálise desde sua "virada ética”, ${ }^{3}$ Butler propõe uma teoria da formação do sujeito que reconhece sua opacidade insuperável, consequência de sua igualmente insuperável relacionalidade. No entanto, essa relacionalidade, mais do que apontar para uma relação entre sujeitos pré-constituídos, ou mesmo entre sujeitos constituídos simultaneamente, postula o primado do Outro, salientando que o recém-chegado ao mundo já se depara com a teia de relações humanas, na qual o bebê já se defronta com um mundo adulto que o antecede, e do qual jamais escapará ou dominará.

Como se vê, a virada ética de Butler é primordialmente uma virada relacional no processo de subjetivação. Esse movimento produz alguns deslocamentos teóricos importantes. Neste artigo, meu objetivo não é passar por todos eles, ${ }^{4}$ mas propor um encontro entre Judith Butler e Hannah Arendt através do cinema, para discutir a relação entre narrativa, psicanálise e subjetivação no caso da personagem protagonista do filme, Guillaume.

$\mathrm{Na}$ primeira seção deste artigo, construirei minha própria narrativa a respeito do ิㅗ relato que Guillaume faz de si mesmo no filme, กิ de modo a articular o principal problema teórico

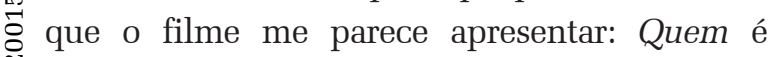
đิ Guillaume? Essa é uma questão posta em termos ขे

I 3 Boa parte dos especialistas na obra de Butler tem con2. siderado que, desde meados dos anos 2000, teria havido ஓं uma "virada ética" em seu trabalho. Discuto as implicações

$\circledast$ normativas dessa virada no pensamento de Butler no arti-

$>$ go Cyfer (2019). Sobre essa e outras questões teóricas na

કิ virada ética de Butler ver Lloyd (2015), e Schippers (2014).

E Emmanuel Levinas é um autor central para se conhecer a స్ virada ética de Butler, especialmente, no que diz respeito à relação entre ética e não violência. Neste artigo, porém, focarei em Hannah Arendt, Adriana Cavarero e Jean LaplanC che, pois esses últimos são as principais referências para a relação que Butler estabelece entre narrativa, psicanálise e subjetivação, uma relação que, conforme já mencionado, corresponde ao objeto deste texto. Em outro artigo, discuto ษ 0 papel de Lévinas na ética de Butler. Ver Cyfer (2019). arendtianos, ou seja, o quem de Guillaume não é redutível ao que Guillaume é, pois,

(...) [a] revelação de "quem" em contradição a "o que” alguém é - os dons, qualidades, talentos e defeitos que se podem exibir ou ocultar - está implícita em tudo o que esse alguém diz ou faz. Só no completo silêncio e na total passividade pode alguém ocultar quem é, mas seu desvelamento quase nunca pode ser alcançado como um propósito deliberado, como se a pessoa possuísse e pudesse dispor desse "quem", do mesmo modo como possui e pode dispor de suas qualidades. Pelo contrário, é quase certo que o "quem”, que aparece tão clara e inconfundivelmente para os outros, permanece oculto para a própria pessoa (ARENDT [1958], 2020, p. 222).

Na segunda seção, procurarei investigar essa questão tendo em vista o modo como Butler a reformula ao articulá-la à psicanálise relacional de Jean Laplanche e à concepção de self narrável ${ }^{5}$ de Adriana Cavarero (2000). Algumas implicações importantes virão dessa mudança: o "quem" não se revelará com clareza nem mesmo para os outros; a opacidade do "quem" para si mesmo será pensada como um desconhecimento que produz conflito psíquico; e a relacionalidade será entendida de modo assimétrico. Em Laplanche (2016), essas são consequências diretas de, de um lado, admitir-se a existência de um inconsciente e, de outro, de entendê-lo no contexto de uma "revolução copernicana" da psicanálise, ou seja, de uma psicanálise que reconhece o descentramento do Eu.

Depois de ter atravessado essa discussão, concluo não com uma explanação capaz de finalmente nos revelar quem é Guillaume, mas sim com uma tentativa de apontar os limites de qualquer narrativa que almeje dar conta completamente da singularidade do sujeito, apontando, com a articulação que Butler faz entre Arendt, Cavarero e Laplanche, para a relação entre ética e política implicada nesses limites.

\footnotetext{
${ }^{5}$ No original em italiano o termo é sé narrabile, a tradução para o inglês, utilizada por Butler, é narratable self. Na tradução em português de Giving an Account of Oneself, a palavra self foi traduzida por si mesmo. Tendo em vista que não há tradução para o português do livro de Cavarero, e que há controvérsia sobre traduzir ou não o termo self, optei neste artigo por traduzir sé narrabile por self narrável.
} 


\section{EU, MAMÃE E OS MENINOS: a cons- trução autobiográfica de Guillaume}

O filme "Eu, mamãe e os meninos" tem início com uma cena em que Guillaume está nos bastidores, diante do espelho, prestes a entrar no palco quando, subitamente, toma a decisão de retirar toda a maquiagem. Já na pele da personagem, procura por “mamãe”, e a resposta vem em uma cena de flashback. Desde então, as narrativas retroativas sobre sua vida no palco irão se intercalar com as cenas em que os fatos se desenrolam em tempo presente diante dos olhos do espectador do filme. Na sequência, Guillaume interpela sua mãe com um entusiasmo infantil e voz efeminada para contar-lhe que encontrou, por acaso, seu primeiro amor, Anna, ao que a mãe responde, "como ele vai?". A conversa se desenrola até o planejamento de sua viagem de verão para a Espanha. Chegando lá, ele é recebido por uma mulher exuberante, Paqui, que lhe ensina a dançar a "sevillana" para uma festa típica da região, a Férias. O rapaz aplica-se nas aulas de dança e imita com precisão os passos que Paqui e suas amigas lhe ensinam. Na festa, porém, nota que sua forma de dançar provoca risos nas pessoas. Somente no final da festa, ele entende a razão dos risos. Ele convida Paqui para dançar, mas ela, dizendo-se muito cansada, entrega-lhe um leque e sugere que convide outra, a Pilar, para uma dança. Esta, porém, recusa o convite e explica a razão: ele dança como uma moça, e não como um homem. A reação de Guillaume é de espanto, pois, aprendeu a dançar seguindo as lições de Paqui, que Pilar agora lhe dizia, eram lições para dançar como uma moça. Logo em seguida, porém, ele pergunta a Pilar: "Eu danço mesmo como uma moça?"; "Sim”, responde Pilar; e ele exclama: "Obrigado Pilar! Não imagina o quanto minha mãe ficará feliz!”

Nessas cenas iniciais já está sugerido algo que durante quase todo o filme será reafirmado: a identificação mimética de Guillaume com o feminino. Sua referência máxima é, evidentemente, sua mãe, a quem se orgulha de imitar a voz e os gestos com tal perfeição que nem mesmo sua avó, a empregada, ou seu pai, são capazes de lhes diferenciar. Em sua relação com Paqui, a imitação gestual feminina se reproduz também com perfeição, sem que $\mathrm{Pa}$ qui pareça se dar conta de que ele não é uma moça. Algo semelhante com a reação da mãe que simplesmente ignora que o primeiro amor a quem Guillaume se refere (Anna) não é ele, não é um rapaz.

Na cena seguinte, já em Paris, a mãe grita a frase que dá nome ao filme no original em francês "Meninos e Guillaume, à mesa!" (Les Garçons e Guillaume, à la table!). Guillaume repete a frase da mãe para seus irmãos, com a mesma entonação autoritária. Nessa frase, está garantido o seu posto especial em relação a seus irmãos. Como ele próprio, em suas últimas falas diante da plateia do teatro irá ressaltar, essa distinção era muito gratificante tanto para a mãe quanto para ele. A mãe podia ver o filho como ela mesma, e o filho, por sua vez, identificando-se com ela, tornava-se mais especial do que apenas mais um menino entre os meninos.

O pai, porém, não parecia satisfeito com essa identificação, e Guillaume mostra saber disso quando declara: "Papai não quer que eu seja uma menina. Sinto pena por mamãe”. Ele não quer frustrar o desejo da mãe de fazer dele seu espelho. Para não perder a exclusividade de seu amor, o objeto de Guillaume não pode ser uma mulher. É por medo de desapontá-la que Guillaume não apenas imita trejeitos femininos, ele realmente acredita ser uma moça, uma moça igual à sua mãe.

A confirmação de que é uma mulher viria do pai, quando este o confundiu com a mãe. Essa era a prova definitiva. Guillaume não tinha mais dúvidas quanto à sua identidade feminina. No entanto, para sua surpresa, a mãe não parecia feliz com seu sucesso. Guillaume, então, especula sobre a razão do desapontamento da mãe, e conclui que reside no fato de ele se parecer demais com ela. Sua saída é buscar referências do feminino em ou- 
tras mulheres. Nessa investigação, ele revela sua fascinação pelo "respirar" das mulheres no qual descobrira a essência do l'air de fille. $\mathrm{Na}$ contemplação de Guillaume, nessas cenas de homenagem ao feminino, os diferentes e belos rostos das mulheres parecem estar sendo ao mesmo tempo investidos como objeto de desejo e funcionando como fonte de inspiração para a construção de sua própria feminilidade: "a partir de então, aprendi com elas, cada suspiro, cada respiração, que faria meu coração bater em uníssono com o coração das mulheres" diz Guillaume.

A realização da feminilidade de Guillaume, porém, será posta em questão quando sofre uma frustração amorosa. Jeremy, o rapaz por quem se apaixonou, e com quem flertou (ou acredita ter flertado), prefere uma menina. Sofrendo com a decepção amorosa, Guillaume desabafa com sua mãe. Ela reage com dificuldade para nomear o que seu filho é, mas, por fim, afirma que "muitos são felizes sendo homossexuais". Ele fica em choque. O sucesso de realizar o feminino, que havia sido confirmado por sua mãe, por Pilar, por sua avó e até mesmo por seu pai (ainda que a contragosto) cai por terra.

Percebendo-se, então, como homem, ele alista-se no exército e passa por psiquiatras e psicanalistas que, de algum modo, sugerem o que apenas um deles verbaliza: "você não gosta mesmo de si próprio?" Confuso a respeito de quem é, compartilha sua angústia com uma ธิ de suas tias, que lhe revela que teve relações is sexuais com mulheres na juventude, mas que nem por isso se tornou uma lésbica, e que a ¿ prova cabal para sabermos quem somos é exิำ perimentar: "até que você experimente, você ¿. não saberá. Se você se apaixonar por um ho๗ొ mem, você é homo, se você se apaixonar por uma mulher, você é hetero".

Guillaume, então, decide experimentar relações com homens. Na primeira tentativa, foge assustado ao ver-se na condição de prostituto (la salope). Na segunda vez, porém, parece entusiasmado e satisfeito com a expectativa de ter relações sexuais com o homem que co- nheceu. No entanto, quando o vê nu, assusta-se com seu pênis e diz: "eu vi um cavalo!". A mãe aparece na cena e confirma: "você sempre teve medo de cavalo!”.

Guillaume então relaciona explicitamente o cavalo ao pênis, e seu pavor de cavalo com o medo de desapontar a mãe. Mas, desta vez, ele decide enfrentar a situação. Inscreve-se em um centro de equitação para domar sua fobia. Em um exercício em que o instrutor lhe recomenda soltar as rédeas, fechar os olhos e confiar no animal, o rapaz liberta-se, confia em si mesmo, pode permitir-se confiar no cavalo, em sua masculinidade, apesar da frustração que isso provocará na mãe.

Essa confiança será reforçada quando é o único convidado homem de um jantar que seria exclusivo para mulheres. Ao invés de integrar-se ao grupo pela imitação, exprime-se com gestos, timbres e olhares que manifestam um "ar de masculinidade" assegurado, que se dá por consolidado quando a anfitriã anuncia: Guillaume e meninas, à mesa! (Guillaume et les filles, à la table!). Ele continuava se distinguindo, mas agora não precisava mais ser uma menina para isso. Suas amigas e, especialmente Amandine, com quem flerta durante o jantar, o reconhecem como especial mesmo sem ser um igual, algo que nem a mãe, nem Paqui, seus irmãos, sua avó, seu pai ou seus colegas de escola foram capazes de enxergar.

Guillaume, então, no palco, diante da plateia e dos espectadores, conclui que ele não era o único a ter medo. Sua mãe também tinha muito medo, "medo de que amasse outra pessoa que não ela”. No entanto, diz ele, "é por causa dela que eu amo e admiro as mulheres". Ele começa a se emocionar, mas se contém, afinal, diz ele, "homens não choram". Enquanto declara no palco sua admiração por sua mãe e o quanto seu amor por ela é seguro e mesmo fonte do amor que sente por Amandine, a câmera foca em uma mulher na plateia, visivelmente emocionada, rodeada por seus irmãos. A atriz, porém, não é a mesma que representou a mãe durante todo o filme. É uma mulher di- 
ferente, cuja imagem até o momento não havia aparecido. Nos créditos finais do filme, saberemos que a atriz que havia encarnado a mãe nas cenas de flashback é na verdade um homem, é o mesmo ator que representa a personagem Guillaume. Seu nome real/artístico é Guillaume Gallienne, um ator premiado da Comédie Française que conta no filme, originalmente uma peça de teatro, sua autobiografia.

O rosto novo e emocionado da mãe, que o admira no palco, é um rosto que ele consegue enxergar como diferente de si mesmo, com quem não precisa se identificar mimeticamente. A cena final, porém, sugere que o desejo da mãe de que Guillaume fosse sua filha não havia sido totalmente superado. No último diálogo do filme, ele anuncia para a mãe que escreverá uma peça de teatro sobre um rapaz que se assume heterossexual para uma família que decretou que ele é homossexual. E a mãe protesta: onde está a prova de que ele é 100\% heterossexual? Finalmente, quando anuncia que ele e Amandine irão se casar, a mãe reage tal como na primeira cena e lhe pergunta, “com quem?”, recusando-se a escutar o desejo heterossexual do filho.

Em uma leitura Freudiana, o desenvolvimento da personagem de Guillaume ao longo do filme parece sugerir a relação entre homossexualidade e narcisismo. ${ }^{6}$ Sua imitação fiel da feminilidade da mãe, e depois de outras mulhe-

${ }^{6}$ Refiro-me aqui especialmente aos artigos de 1910, "Uma recordação de infância de Leonardo da Vinci”, "O caso Schreber", de 1911 e "Introducão ao Narcisismo", de 1914. A relação entre homossexualidade e narcisismo será bastante problematizada por teorias psicanalíticas posteriores, sendo a de Jean Laplanche uma delas (Laplanche, [1987]1991, p. 73 e ss.). Ainda assim, cabe observar que declarações de Freud desse mesmo período e posteriores indicam que a relação que se estabelece entre narcisismo e homossexualidade nesses textos não implica necessariamente a patologização desta última. Como observa Vieira (2009), "diante da criminalização da homossexualidade, Freud aceita conceder uma entrevista, em 1903, ao jornal (...) Die Zeit, em defesa de um homem acusado por práticas homossexuais. Em 1930, ele assina uma petição pela revisão do código penal e a supressão do delito da homossexualidade entre adultos que consentem. Não esqueçamos também que em 1935, ele escreve uma carta endereçada a uma mãe norte-americana que havia lhe solicitado ajuda em relação às condutas e comportamentos que ela considerava anormais por parte de seu filho”. Vieira (2009, p. 497). A resposta de Freud é bastante conhecida: a homossexualidade não é uma doença nem um vício moral, grandes contribuições para a humanidade nos foram dadas por homossexuais ilustres como Platão, Michelangelo e Leonardo da Vinci, e é uma grande injustiça e crueldade tratá-la como crime. res, indicaria uma fixação intensa na relação com a mãe nos primeiros anos de vida que se transforma em identificação com ela. Imitando a mãe buscaria recuperar o intenso laço afetivo primário que fazia dele um depositário da projeção narcísica da mãe. Em outras palavras, a fixação dele em sua identificação com a mãe permitia-lhe reviver o ideal da perfeição infantil.

O rapaz, porém, começa a se desvencilhar desse ideal quando enfrenta o temor de sua masculinidade entendido como o medo de decepcionar a mãe. Quando perde esse medo, percebe que ela também, sua mãe fálica, poderosa, andrógina, sua "mãe-abutre", 7 também tem muito medo. Talvez nesse momento tenha podido dissociar seu Ideal do Eu de sua mãe. Agora seu fascínio está em Amandine, "a mulher mais linda do mundo!”. Uma mulher que consegue ser "linda, adorável e bela ao mesmo tempo!”. Seu Ideal do Eu parece agora transferir-se para o objeto com a intensidade que o fazem os enamorados que, desistindo de atingir seu próprio ideal, projetam-no em outro.

Essa parece ser o que Freud chamou de "cura pelo amor" que "via de regra, [o sujeito] prefere à cura psicanalítica. Poderíamos ficar satisfeitos com essa saída, se ela não trouxesse todos os perigos de uma opressiva dependência de tal salvador" (Freud, 1914, p.49).

Talvez não seja uma coincidência que a superação do sofrimento psíquico de Guillaume seja sintetizada na última cena de flashback com duas novidades que conta à mãe: a de que escreverá uma peça de teatro autobiográfica, e a de que se casará com Amandine. É possível que esses dois projetos somente sejam realizáveis na medida em que atuam em colaboração um com outro. O casamento com Amandine, como investimento em um objeto idealizado, e

7 "Mãe-abutre" remete à análise que Freud faz da recordação de infância de Leonardo da Vinci de que, quando ainda era uma criança de berço, um abutre se aproximou, abriu-lhe a boca com a cauda, e bateu muitas vezes a cauda contra seus lábios (Freud, 1910). Freud recupera a relação simbólica entre abutre e mãe nos hieróglifos antigos egípcios, nos quais a mãe é representada como abutre. Mas a "mãe-abutre" não era qualquer mãe, era uma mãe auto-suficiente, sem pai, que gera seu filho sem a participação do macho, sendo fecundada pelo vento (Freud, 1910). 
o roteiro autobiográfico, como forma de sublimação que, embora instigada pela idealização, não é redutível a ela (Freud, 1914, p.49).

Freud estabelece a distinção entre sublimação e idealização da seguinte forma:

A formação do ideal do Eu é frequentemente confundida, em prejuízo de sua compreensão, com a sublimação do instinto [pulsão]. Haver trocado seu narcisismo pela veneração de um elevado ideal do Eu não implica ter alcançado a sublimação de seus instintos [pulsões] libidinais. É certo que o ideal do Eu requer tal sublimação, mas não pode forçá-la; a sublimação continua sendo um processo particular, cuja iniciação pode ser instigada pelo ideal, mas cuja execução permanece independente da instigação. (Freud, 1914, p. 40-41).

Assim, tanto a descrição de Amandine, como uma princesa perfeita, quanto a estória do despertar de sua masculinidade podem ser lidas, ou melhor escutadas, como narrativas em que a veneração do objeto instiga o processo particular da sublimação que Guillaume alcança ao transformar sua vida em um roteiro teatral, que mais revela pelo que fantasia, do que pelo que informa, mais pelo que tem de sonho, do que de realidade.

Com efeito, em seu relato, a estória é contada em uma atuação teatral presente e uma narrativa em flashback, em um tempo atual e outro passado. No entanto, o teatro é filmado e os espectadores não são realmente a plateia. Guillaume fala conosco, mas não estamos diani te dele. Tanto a atualidade do tempo quanto a ஸิे realidade do espaço têm algo de alucinatório.

: $\overbrace{}^{\circ}$ Além dessa complexidade temporal e 을 espacial, o filme desconcerta pela sinuosidad de de sua narrativa. O roteiro é autobiográfico, $\stackrel{7}{\sim}$ mas o filme não pretende ser um documenin tário. Sua vida é contada por ele mesmo em uma história saturada de fantasias, de episódios que soam inverossímeis, de personagens caricatas que não parecem reais. Assim como em qualquer biografia, a vida de Guillaume é repleta de imaginação. Mas, assim como as lembranças de infância de Leonardo da Vinci, são justamente esses elementos ficcionais de seu filme/peça/biografia que revelam, inadvertidamente, os meandros de sua subjetividade.

Assim, quando proponho interpretar a narrativa autobiográfica de Guillaume não pretendo tomá-la como uma sucessão coerente, verídica ou inverídica, de eventos históricos. Meu ponto é recuperar seu roteiro teatral como um enigma inscrito em uma estória de vida entranhada na relação com os outros desde o início, outros que lhe habitam e que comprometem seu domínio sobre a definição de quem é. Minha intenção no que segue deste artigo é explorar esse enigma tendo em vista o modo como Judith Butler articula a metapsicologia de Jean Laplanche à narrativa em Adriana Cavarero e Hannah Arendt.

\section{GUILLAUME E A VIDA PSÍQUICA DA NARRATIVA}

No que se refere especificamente à apropriação da concepção de narrativa de Hannah Arendt, ${ }^{8}$ Butler segue, em grande medida, a leitura e reformulação propostas pela filósofa italiana Adriana Cavarero, especialmente em seu livro Tu Che Mi Guardi, Tu Che Mi Racconti:. Filosofia della Narrazione, de $1997 .{ }^{9}$ Cavarero sintetiza o principal problema teórico de seu livro da seguinte forma: quem poderá compreender o significado da nossa estória de vida quando esta estiver completa? (Cavarero, 2000, p.1), e segue explorando essa questão por caminhos explicitamente arendtianos.

Por meio de uma discussão sobre a relação entre narrativa e subjetividade nos mitos de Édipo e Ulisses, Cavarero investiga quem é o herói, tendo em vista a relacionalidade implicada em suas respectivas estórias de vida.

\footnotetext{
${ }^{8}$ Essa não é a única influência de Arendt no trabalho de Butler mais recente. Sobre o papel que Arendt passa a cumprir na relação entre performance a ação política de Butler, além da relação entre a concepção de pluralidade arendtiana e a noção de co-habitação de Butler cf. Duarte (2016). Veja-se também, por exemplo, Shippers (2014), Beenhabib(2013).

${ }^{9}$ Esse é o título original do livro de Cavarero, cuja primeira edição italiana foi publicada em 1997. A tradução para o inglês foi publicada em 2000, sob o título Relating Narratives: storytelling and selfhood. Tradução: Paul Kottman.
} 
Apesar das diferenças de suas biografias, eles somente conseguem dar conta de sua própria estória por meio das estórias que outras pessoas lhes contam. Com isso, Cavarero, fazendo referência explícita a Arendt salienta que "o quem que cada um de nós é nos é revelado pelos outros (...)" (Cavarero, 2000, p.22).

Mas seu ponto não é apenas salientar que o sujeito seria co-autor de uma narrativa produzida na teia de relações humanas. ${ }^{10}$ Mais do que isso, Cavarero propõe, com Arendt, que a estória não tem autor (Arendt, 1958, 186). Assim, dessa perspectiva, não se poderia dizer que a ação pressuponha um sujeito anterior à ação ou um autor que inventa e controla sua narrativa. O ator é ele próprio "revelado por suas ações, das quais a própria estória resultou" (Cavarero, 2000, p.28). Assim, o relato que fazemos de nós mesmos, as estórias que contamos sobre nossa vida somente podem ser apreendidas fora do domínio do autor soberano que conhece a verdade sobre si mesmo.

Esse é o postulado fundamental para que Cavarero formule a sua concepção de self narrável, com a qual introduz a relação entre narrativa arendtiana e o desejo de sabermos sobre nossa singularidade, de sabermos quem somos "realmente". Cavarero pensa a relação entre narrativa e desejo tendo em vista algo que Butler (1997) já havia explorado em seu livro A Vida Psíquica do Poder: o desejo pela identidade. No entanto, em Relatar a Si Mesmo, ao introduzir a leitura que Cavarero faz de Arendt para explorar essa mesma questão, Butler passaria a situar o desejo pela identidade no contexto de uma teoria do reconhecimento que parte do primado do outro. ${ }^{11}$

${ }^{10} \mathrm{O}$ contraste entre autor e ator é crucial para diferenciar a ação em concerto de uma autoria conjunta, um ponto que distancia a leitura que Cavarero faz da relação entre subjetividade, narrativa e agência em Arendt daquela que Seyla Benhabib propõe em seu modelo narrativo de self (Benhabib, 1999). Em um trabalho em andamento intitulado Paradigm Wars of Feminist Theory: Judith Butler and Seyla Benhabib revisited" (prelo), discuto a divergência entre as leituras que cada uma dessas autoras faz de Arendt tendo-se em vista a influência de Cavarero em Butler, e a de Habermas em Benhabib.

${ }^{11}$ Discuto essas mudanças nos artigos Cyfer (2019) e Cyfer $\left(2019^{\mathrm{a}}\right)$.
Em Cavarero, o desejo pela identidade é um desejo pela unidade do sujeito, um desejo de vermos nossa subjetividade fielmente traduzida em uma estória. Esse desejo, que jamais se realiza completamente, é o motor que impulsiona a ação. Nesse ponto, Cavarero distancia-se de Arendt ao afirmar que esta última teria privilegiado a categoria de singularidade em detrimento da categoria de unidade. Para ela, não é possível marginalizar nenhuma delas, pois, a singularidade é revelada em uma ação que é motivada pela perda da unidade primária que não será jamais recuperada novamente, mas que nem por isso deixará de ser incessantemente desejada (Cavarero, 2000, p.37 e ss).

À primeira vista, esse desejo por unidade movido pela falta parece sugerir uma noção de inconsciente no self narrável. No entanto, Cavarero é bastante clara em rejeitar uma interpretação psicanalítica desse desejo. A razão disso parece estar na pressuposição de que a psicanálise poderia comprometer o caráter inescapavelmente relacional da formação do sujeito com investigações introspectivas de seu aparelho psíquico (Cavarero, 2000; Guaraldo, 2007; Cyfer, 2019a; Ccavarero; Bertolino, 2008).

Butler, porém, aposta na "revolução copernicana” de Laplanche para introduzir inconsciente e conflito psíquico no sujeito sem comprometer o caráter relacional da subjetivação. Segundo o próprio Freud, a Revolução Copernicana na astronomia, a teoria da evolução Darwinista e a psicanálise teriam sido as três grandes "afrontas por parte da pesquisa científica ao narcisimo geral, ao amor próprio da humanidade" (Freud, 1917, p. 144-145). Mas, para Laplanche, Freud não teria levado essa ideia às últimas consequências, vacilando entre o descentramento e o centramento do sujeito; Freud teria sido, assim, "seu próprio Copérnico, mas também seu próprio Ptolomeu” (Laplanche, 1992a, p. XI.). No entanto, a radicalidade da psicanálise estaria, para Laplanche, em não domesticar o descentramento, em não ceder à tentação de recusar a observação psicanalítica de que "o eu não é mestre em sua própria casa". 
Para levar adiante a revolução psicanalítica iniciada por Freud, Laplanche acredita que esse descentramento precisa não apenas ser mantido, mas pensado em duas dimensões:

\section{Ei-nos chegado ao ponto que consideramos como o essencial a esta revolução copernicana iniciada por Freud; o descentramento, [que] na realidade, é duplo; a outra coisa (das Andere) que é o incons- ciente, só se mantém na sua alteridade radical pela outra pessoa (der Andere): em suma, pela sedução. (Laplanche, 1992a, p.XI)}

Laplanche retoma a teoria da sedução abandonada por Freud e reivindica sua generalidade, ou seja, a sedução entre adulto e criança não seria uma característica apenas de relações patológicas que possam causar sintomas psíquicos. Ela é própria de toda relação primária. Mas o que caracteriza essa sedução é a assimetria fundamental entre adulto e bebê, entre um ser dotado de um inconsciente e o outro ser, cujo inconsciente será produzido por essa relação. A assimetria, assim, não sugere um domínio total do adulto sobre si, já que o que produz a assimetria é justamente o que o adulto não domina ou possui, aquilo que é desconhecido para si mesmo (Laplanche, [1987] 1992b, p.138 e ss).

Essa é a "situação antropológica fundamental” (Laplanche, [2002] 2018, p.104-115). $\mathrm{O}$ adulto envia uma mensagem, que é opaca até para si mesmo, para um bebê que não tem como lidar com ela. A mensagem é enigmática, ํํ mas é esse mesmo enigma com que o Outro เo nos depara que é a

(...) mola propulsora do tempo. É com base no enigma apresentado pelo mundo adulto que o sujeito se temporaliza, cria um romance familiar, cria uma história para si mesmo. (...) A narrativa (storytelling) [é] uma das formas de responder ao enigma. Será sempre desigual ou insuficiente para o enigma. Sempre haverá um resto. Felizmente, nenhuma narrativa será a perfeita, nenhuma permitirá resolver o enigma de modo exato. (Laplanche, [2002], 2015, p. 712)

A insuficiência de toda narrativa, de todo relato de si, em Laplanche traz implicações éticas na prática clínica, e em Butler será crucial para o modo como entrelaça ética, política e vulnerabilidade:

\begin{abstract}
Sou atravessada por razões que não consigo recuperar totalmente, que permanecem enigmáticas, que me acompanham como se fossem minha alteridade familiar, minha própria opacidade privada, ou talvez não tão privada assim. Eu falo como um "eu”, mas não cometo o erro de pensar que sei exatamente tudo o que estou fazendo quando falo dessa maneira. Descubro que minha própria estranheza para comigo mesma é, paradoxalmente, a fonte de minha conexão ética com os outros (Butler, [2005], 2015, p.112).
\end{abstract}

Se não podemos desvendar a nós mesmos, nem tampouco aos outros, se toda estória que contarmos de nós mesmos já estará entranhada na relação com os outros enigmáticos, a ética que me conecta aos outros ancora-se justamente no desconhecimento, é uma ética que ao invés de resistir ao enigma, abre-se para ele, uma abertura que, para Laplanche, é pura

(...) inspiração. Na minha visão, não pode haver criatividade sem essa reativação do enigma do outro, sem o questionamento do trabalho criativo que nunca é completamente bem sucedido em realizar ou compreender. A pessoa criativa é aquela que busca para sempre colocar uma existência e uma relação em uma estória- em uma narratividade- ainda que esta jamais seja suficiente (LAPLANCHE, [2002], 2015, p. 712.).

O que Laplanche chama de inspiração, portanto, depende de se acolher o desconhecimento, ao invés de lutar contra ele buscando o domínio de si ou do outro. Afinal, o trabalho criativo não se realizaria sem que pudéssemos encontrar um lugar para os enigmas de nossos mundos, interior e exterior, sem que pudéssemos abrigar os mistérios de todos nós. Já a ética da vulnerabilidade de Butler compromete-se com esses mistérios, com o risco da revelação pública do quem, que não podemos compreender nem dominar completamente, que é jogado no mundo, numa teia de relações humanas que lhe antecede.

A influência de Arendt é evidente nesse ponto. No entanto, é preciso salientar que a narrativa arendtiana é introduzida no processo 
de subjetivação de Butler por intermédio da releitura que Cavarero faz de Arendt ao formular sua concepção de self narrável. Afinal, é na introdução do desejo pela narrativa, que não está em Arendt, que Butler traça sua trilha para explorar o desejo pela identidade no contexto de um processo de subjetivação relacional, característico de sua virada ética. Assim, é usando Arendt contra Arendt, como uma vez disse Benhabib, que Butler articula narrativa e identidade em sua obra mais recente. No entanto, isso não bastará. Butler precisará também usar Cavarero contra Cavarero para explorar o desejo pela identidade com a psicanálise, como vem fazendo ao longo de toda a sua obra.

\section{QUEM É GUILLAUME?}

Será Guillaume uma menina? Será Guillaume um menino? Hétero ou Homossexual? Depois de conduzir seus espectadores pela estória de sua vida, Guillaume parece mais calmo e sereno. Poderíamos imaginar que ele finalmente pôde superar o conflito psíquico que o afligia, descobrir quem é e construir uma relação amorosa verdadeira. No entanto, se nos propusermos a interpretar sua narrativa com todos os enigmas e conflitos que o filme nos expõe, talvez pudéssemos deixar essas questões sem resposta, poderíamos propor uma recusa de uma explicação conclusiva que definisse Guillaume como hétero ou homo, como menina ou menina. Afinal, se decretássemos agora qual é a sua identidade, estaríamos longe de explorar sua singularidade, estaríamos antes substituindo a questão "quem é Guillaume?” pela pergunta “o que é Guillaume?”. Se prosseguirmos com Butler e acrescentarmos à noção de singularidade de Arendt a psicanálise de Laplanche, poderíamos dizer ainda que qualquer narrativa coerente sobre Guillaume estaria silenciando seu inconsciente em nome de uma síntese da estória. Como diz Laplanche, em suas contundentes críticas à aproximação entre psicanálise e hermenêutica,
Freud incessantemente declarou-se contra qualquer tipo de síntese. De um lado, nenhuma síntese seria encontrada no $I d$, que era governado pela coexistência sem coerência; de outro, o analista deveria dar-se por satisfeito com analisar, sem propor nenhum tipo de "psicosíntese". (....) em 1900 [Interpretação dos Sonhos] o método analítico já está completo e ele não é em nenhum sentido uma tradução, uma compreensão ou uma leitura. O método consiste em uma "de-tradução", no rastreamento dos elementos descritos como inconscientes (...) (Laplanche, 1997, p. 07-08).

Para Laplanche, a de-tradução está implicada no método analítico da associação-dissociação, o método da psicanálise por excelência. É o método que separa, divide e fragmenta a narrativa, que coloca em questão os ideais subjacentes a cada estória e que problematiza a síntese definitiva que toda e qualquer narrativa possa oferecer (Laplanche, 1991, p. 07-10). No entanto, conforme salienta Butler, recusar a síntese não é o mesmo que

celebrar certa noção de incoerência, mas apenas
destacar que nossa "incoerência” define o modo
como somos constituídos na relacionalidade, im-
plicados, obrigados, derivados, sustentados por um
mundo social além de nós e anterior a nós". (Butler,
[2005] 2015, p.87).

Butler reconhece que a noção de resíduos não narráveis dos relatos que fazemos de nós mesmos é objeto de críticas que receiam que tais resíduos possam matar o sujeito, sua capacidade de ação e de conhecer e dominar a si mesmo e ao mundo. No entanto, pergunta-se Butler, "preciso conhecer a mim mesma para agir com responsabilidade nas relações sociais?" Sua resposta é: "em certa medida, sim" e logo pergunta retoricamente, "mas há um valor ético no meu desconhecimento?" (Bulter, [2005], 2015, p. 87).

O valor ético de reconhecer que há algo em mim e nos outros que jamais poderei desvendar é o de acolher a estrangereidade, o Das Umheimliche, que vive em todos nós. Ainda que cause certa inquietação reconhecer os limites do domínio e conhecimento de si, "essa é uma aflição necessária” para uma ética cuja 
noção de responsabilidade dispensa um "eu auto-suficiente" e, na verdade, o rejeita com um sujeito dominador (Butler [2005], 2015, p. 87). Em seu lugar, propõe um sujeito cindido, vulnerável e parcialmente opaco para si mesmo, mas que é capaz de ação na medida em que se arrisca a se revelar

\begin{abstract}
precisamente nos momentos de desconhecimento, quando aquilo que nos forma diverge do que está diante de nós, quando nossa disposição para nos desfazer em relação aos outros constitui nossa chance de nos tornarmos humanos (Butler, [2005], 2015, p. 171).
\end{abstract}

Seguindo por esse caminho, a única coisa que me arriscaria a afirmar a respeito de Guillaume é que ele é uma pessoa criativa. Transformar sua vida em uma peça de teatro (e depois em filme que preserva a linguagem teatral) parece ter sido a forma que Guillaume, o menino/ator/personagem, encontrou para abrir sua estranheza familiar para a criatividade, para borrar a fronteira entre a narrativa ficcional e a realidade, de modo a permitir a transformação de seu sofrimento naquele "suave narcótico" que afrouxa os vínculos com o mundo real: a arte (Freud, 1929/30, p.37). E foi justamente o teatro, "a arte política por excelência, (...), a única arte cujo assunto é, exclusivamente, o homem em relação com os outros homens" (Arendt, [1958], 2020, p. 233), que entorpeceu Guillaume.

Acredito que essa tentativa de interpretação ou talvez de "de-tradução" da estória de Guillaume poderia animar uma conversa entre Arendt e Butler depois de assistirem ao filme Eu, mamãe e os meninos. Mas Butler não chegaria ao cinema sozinha. Ela teria de apresentar Arendt, ao menos, a outros dois convidados, Adriana Cavarero e Jean Laplanche. Depois do filme, iriam todos se reunir em debates intensos, talvez até ferozes, que certamente não levariam a nenhuma conclusão sobre a identidade de Guillaume. No entanto, isso não seria um problema. Ao contrário, afinal, é justamente no caráter inconclusivo e opaco de nossas estórias que Butler vê a contribuição de Arendt, Cavarero e Laplanche para uma ética que busca, nos enigmas da subjetividade, a inspiração para novos começos.

Recebido para publicação em 08 de fevereiro de 2020 Áceito em 12 de agosto de 2020

\section{REFERÊNCIAS}

ARENDT, H. A Condição Humana, tradução Roberto Raposo e revisão técnica de Adriano Correia. Rio de Janeiro: Forense Universitária, [1958], 2020.

BENHABIB, S. Ethics without Normativity and Politics without Historicity On Judith Butler's Parting Ways. Jewishness and the Critique of Zionism. v. 20, Issue1, March 2013

BENHABIB, S. Sexual Difference and collective identities: a new global Constellation. Signs, v. 24, n. 2, 1999.

BUTLER, J. Relatar a Si Mesmo: crítica da violência ética. Tradução Rogério Bettoni. Belo Horizonte: Autêntica Editora, [2005], 2015.

CAVARERO, A. Relating Narratives: storytelling and selfhood. London \& New York: Routledge 1997], 2000.

CAVARERO, A; BERTOLINO, E. Beyond Ontology and Sexual Difference: an Interview with the Italian Feminist Philosopher Adriana Cavarero. Differences 1, May; v. 1, n. 1, p. 128-167, 2008.

CYFER, I. What's the trouble with humanity? A feminist critique of Judith Butler's ethics of vulnerability. Digithum, v. 23,2019 .

CYFER, I. Arendtian Narratives: Adriana Cavarero and Judith Butler on the agency and opacity of the self. Rosenfield, K; Gonçalves Silva, F (Orgs). Martin Heidegger e Hannah Arendt no seu tempo - e no nosso. Porto Alegre, RS: Editora Fi, 2019a.

DUARTE, A. Judith Butler e Hannah Arendt em dialogo: repensar a ética e a política. Paraná: Curitiba PUCPress, 2016.

FERNANDES, A. L. Cinema e Psicanálise. In: Rio de Janeiro: Estudos de Psicanálise. Rio de Janeiro. n. 28, p. 69-74, set. 2005.

FREUD, S. (1905). Três Ensaios Sobre a Teoria da Sexualidade. In: Sigmund Freud: Obras Completas. São Paulo: Companhia das Letras. Tradução: Paulo César Lima de Souza. 2016.

(1910). Uma Recordação de Infância de Leonardo da Vinci. In: Sigmund Freud: Obras Completas. São Paulo: Companhia das Letras. Tradução: Paulo César Lima de Souza. 2016.

. (1911). Observações Psicanalíticas sobre um caso de paranoia [dementia paranoides] relatado em uma autobiografia ["O Caso Schreber”]. In: Sigmund Freud: Obras Completas. São Paulo: Companhia das Letras. Tradução: Paulo César Lima de Souza. 2010.

(1914). Introdução ao Narcisismo. In: Sigmund Freud: Obras Completas. São Paulo: Companhia das Letras. Tradução: Paulo César Lima de Souza. 2010.

(1917) Uma Dificuldade da Psicanálise. In: Sigmund Freud: Obras Completas. São Paulo: Companhia das Letras. Tradução: Paulo César Lima de Souza. 2010. 
(1929/30). O Mal-Estar na Civilização. In: Sigmund Freud: Obras Completas. São Paulo: Companhia das Letras. Tradução: Paulo César Lima de Souza. 2010

GUARALDO, O. "Pensadoras de Peso: O pensamento de Judith Butler e Adriana Cavarero". Revista de Estudos Feministas, v. 15, (3): 336, set./dez., p. 663-677, 2007.

LAPLANCHE, J. Narrativité et herméneutique: quelques propositions. In: Temps et récit, 3. Paris: Le Seuill, 1991.

. La Révolution Copernicienne inachevée. Tavaus (1967-1992), Paris: Aubier, 1992a, p. XI.

[1987], Novos Fundamentos para a Psicanálise. Tradução Cláudia Berliner: revisão da tradução Eduardo Brandão. São Paulo. Martins Fontes, 1992b.

Psychoanalysis as Anti-Hermeneutics. In: Radical Philosophy, 79, sept/Oct, 1996.
Interview with Jean Laplanche (conducted by Gisele Danon and Didier Lauru). In: Psychoanalysis Review, 102 (5), October, 2015.

Sexual: a sexualidade ampliada no sentido freudiano- 2000-2008 Porto Alegre, São Paulo: Dublinense, 2018.

LLOYD, M.(ed). Butler and Ethics. Edinburgh University Press, 2015.

SCHIPPERS, B. The Political Philosophy of Judith Butler. New York \& London: Routledge, 2014.

VIEIRA, L. As Múltiplas Faces da Homossexualidade na obra freudiana. Revista Mal-estar e Subjetividade. Fortaleza, v. 9, n. 2, p. 487-525, jun/2009. 


\section{JUDITH BUTLER AND HANNAH ARENDT GO TO THE MOVIES: narrative, psychoanalysis and subjectification in the film Me, Myself and Mum}

\section{Ingrid Cyfer}

In this article, I propose an analysis of the film Me, Myself and Mum (Les garçons et Guillaume, à table! Directed by Guillaume Gallienne. France 2013) with a view to a political and relational perspective of the connections between psychoanalysis, narrative and subjectivation process. My inspiration for this is in the way Judith Butler articulates these dimensions in her book Giving an Account of Oneself (2005). In this work, Butler proposes a theory of the formation of the subject in which Hannah Arendt's conception of narrative plays a fundamental role, after being reformulated by Adriana Cavarero's conception of narrable self and combined with Jean Laplanche's relational metapsychology. In this text, my goal is to invite Butler and Arendt to the movies to later discuss the relationship between narrative, psychoanalysis and subjectivity in view of the link between ethics and politics that the story in which Guillaume tells us about who he is can inspire.

KEYwORDS: Hannah Arendt. Judith Butler. Subjectivation. Psychoanalysis. Narrative.

\author{
JUDITH BUTLER ET HANNAH ARENDT \\ VONT AU CINÉMA: narration, psychanalyse \\ et subjectivation dan le film Les Garçons et \\ Guillaume, à table!
}

Ingrid Cyfer

Dans cet article, je propose une analyse du film Les Garçons et Guillaume, à la Table (Realisation Guillaume Galliene, France, 2013) en vue d'une perspective politique et relationnelle des liens entre psychanalyse, narration et processus de subjectivation. Mon inspiration pour cela réside dans la façon dont Judith Butler articule ces dimensions dans son livre Le Récit de Soi (2005). Dans ce travail, Butler propose une théorie de la formation du sujet dans laquelle la conception de la narration d'Hannah Arendt joue un rôle fondamental, après avoir été reformulée par la conception d'Adriana Cavarero du soi narrable et combinée avec la métapsychologie relationnelle de Jean Laplanche. Dans ce texte, mon objectif est d'inviter Butler et Arendt au cinéma pour discuter plus tard de la relation entre narration, psychanalyse et subjectivité au vu du lien entre éthique et politique que l'histoire dans laquelle Guillaume nous raconte qui il est peut inspirer.

Mots CLÉs: Hannah Arendt. Judith Butler. Subjectivation. Psychanalyse. Narrative.

Ingrid Cyfer - Pós- Doutorado em Dartmouth College- EUA no Departamento de Filosofia. Doutorado em Ciência Política pela USP, com estágio doutoral na New School for Social Research. Professora do Departamento de Ciências Sociais da Universidade Federal de São Paulo. Integra o Núcleo de Pesquisa Teoria Crítica e Psicanálise, vinculado ao Núcleo Direito e Democracia do CEBRAP. É membro do Departamento de Formação em Psicanálise do Instituto Sedes Sapientiae. Suas mais recentes publicações são: A bruxa está solta: os protestos contra a visita de Judith Butler ao Brasil à luz de sua reflexão sobre ética, política e vulnerabilidade. Cadernos Pagu (53), 2018; Teoria Crítica e Feminismo: discutindo a relação. In: Vitale, Denise; Nagamine, R. (Org.). Gênero, Direito e Relações Internacionais: debates de um campo em construção. 1ed.Salvador, Bahia: EDUFBA, 2018, p. 7-25; Arendtian Narratives: Adriana Cavarero and Judith Butler on the agency and opacity of the self. In: Rosenfield, K; Silva, Felipe Gonçalves (Orgs.) Martin Heidegger e Hannah Arendt no seu tempo - e no nosso. Porto Alegre, RS: Editora Fi, 2019; What's the trouble with humanity? A feminist critique of Judith Butler's ethics of vulnerability. In: Teixeira, M e Bueno, A. (Special Section: The Politics of Social Suffering). Digithum, n. 23, 2019. 